\title{
Study on the Intentions of Strategic Alliances in Enterprises
}

\author{
Liang Jia-qiang \\ School of Management, Shandong University of Technology \\ Zibo City, Shandong Province, China \\ Email: 623537348 [AT] qq.com
}

\begin{abstract}
Since the 1980s, the strategic alliance, a new form of enterprise organization, has made great progress, and its breadth and depth have been greatly improved, which has led to the development of strategic alliances in all walks of life. In this paper, from the system, technology, organization and concept of strategic alliance, the dynamics of strategic alliance are systematically explained, with a view to promoting a more in-depth study of this problem.
\end{abstract}

Keywords_- strategic alliance, intention, enterprise strategy

\section{INTRODUCTION}

Since the 1980s, western enterprises have begun to adjust their competitive relationship strategically, and strategic alliance, as an important organizational innovation, as a cooperative arrangement between enterprise organizations, and as an opportunity for enterprises to gain a leading competitive advantage, has gained rapid recognition and development.

The formation of strategic alliance is aimed at obtaining long-term strategic benefits of enterprises, in order to obtain long-term competitive advantage of enterprises as the main reason, these intentions are mainly reflected in the system, technology, organization and concept of these four aspects.

\section{DEFINITION OF STRATEGIC ALLIANCES}

Strategic Alliance originated when Japanese companies worked together to buy advanced technology, and this concept is evolving into an academic concept proposed by the president of the DEC corporation in the United States. Sierra (1995) considered the strategic alliance is a competitive alliance, a partnership of interests between companies that are already in a competitive position [1]. Porter (1986), a renowned management scientist, first proposed the academic definition of strategic alliance from the perspective of economic theory: strategic alliance is a long-term agreement between enterprises that goes beyond normal market transactions but does not reach the level of consolidation [2]. Gulati (1999) believed technology alliances as a group of organizations that respond to intense competition by finding partners to gain a sustainable competitive advantage through alliances ${ }^{[3]}$. Other researchers see strategic alliances as a cooperative arrangement between business organizations, as an opportunity for companies to gain a leading competitive advantages ${ }^{[4]}$. This paper holds that the enterprise strategic alliance is two or more enterprises with certain advantages in order to specific strategic objectives, through equity or contract, the establishment of long-term and stable cooperative relations.

The various definitions, although somewhat different, clearly have common characteristics, including:

(1)The looseness of the organization: The enterprises participating in the alliance are a kind of partnership, which goes beyond the general transaction relationship and does not exist the subordinate relationship between control and control, and maintains the independence and equality of their respective enterprises while working closely together;

(2)The mutual benefit of cooperation: Strategic alliances are basically partnerships that utilize each other and enhance competitiveness, hoping to gain benefits greater than their respective independent or opposing behaviors;

(3)The fundamental of competition: Cooperation is to better competition, cooperation between alliance enterprises is not necessarily all-round, and cooperation is often carried out in an agreed field;

(4)The long-term nature of the strategy: Strategic alliance is a kind of long-term arrangement which aims to create long-term competitive advantage for enterprises and belongs to the strategy at the company level.

\section{THE THEORETICAL EXPLANATION OF THE INTENTIONS OF STRATEGIC}

\section{ALLIANCES}

In theoretical research, the theoretical explanation of the intentions of strategic alliances presents interdisciplinary and cross-category characteristics. Specifically, the researchers do not separately from the single point of view of management, but combine the theoretical explanations and research results of economics, sociology and other disciplines, and try to make a reasonable theoretical explanation of the strategic alliance of enterprises from a more comprehensive perspective. In general, these theoretical explanations of the intentions of strategic alliances mainly include the following more representative views: 


\subsection{The view of transaction costs}

The transaction cost theory studies how to determine the boundaries of an organization in order to minimize the sum of the organization's production costs and transaction costs. Transaction costs are all the costs required to accurately obtain market information and the costs associated with contract signing and negotiation, as reflected in the cost of discovering price information and a range of costs such as contract negotiation, signing, performance, or default disposal [5]. A solid long-term institutional arrangement of strategic alliances as a contractual connection between alliance enterprises can reduce the opportunity behavior of alliance partners and reduce the transaction costs between crossregional and cross-industry enterprises. Although the establishment and implementation of strategic alliances also require costs, the implementation of strategic alliances is profitable as long as the increased costs are less than the reduction in transaction costs resulting from the alliances.

\subsection{The view of resources}

According to the view of resources, enterprises with competitive advantages have resources that other enterprises do not have, and these resources are mostly heterogeneity resources such as intangible corporate culture, human capital, knowledge and adaptability. These unique heterogeneity resources bring excess returns for enterprises. Companies with competitive advantage tend to monopolize such resources, making them scarce, irreplaceable and difficult for competitors to imitate. These key heterogeneity resources are not concentrated in a particular enterprise or organization, but are scattered. Enterprises use each other's key resources to enhance their competitive advantage through strategic alliances, which is a resource advantage that no single enterprise can match ${ }^{[6]}$.

\subsection{The view of the core competency}

The core competency theory emphasizes the ability to make effective use of all the resources of an enterprise. The key capabilities that an enterprise can uniquely utilize a resource that other enterprises do not have or lack are the core competency of the enterprise, such as capital operation ability, public relations ability, etc. ${ }^{[7]}$. The scarcity, difficulty of imitation and irreplaceability of the core ability of enterprises enable them to achieve cooperation and win-win through complementary advantages, and strategic alliance is an effective way to achieve this goal.

\subsection{The view of the organizational learning}

The organizational learning view holds that the organization is a dynamic structure with active learning ability, and emphasizes the relationship between enterprise learning ability and competitive advantage. The knowledge structure of an enterprise is complex, including coding knowledge and empirical knowledge, in which empirical knowledge is a knowledge that can only be obtained through the learning process such as observation or practice ${ }^{[8]}$.

Strategic alliance is an important way for enterprises to learn, and the alliance enterprises can carry out in-depth exchanges in the field of cooperation within the alliance, learn from each other to supplement their knowledge stock, especially to increase the experience knowledge implied within the enterprise, so as to realize the transfer and sharing of knowledge within the alliance, improve the core competitiveness of the alliance partners, and achieve the strategic objectives of the enterprise.

\subsection{The view of the value chain}

The value chain theory holds that enterprises are a collection of economic activities, including design, production and sales and so on. Every economic activity is part of a value system, called a value chain. According to the value chain theory, it is necessary for enterprises to effectively manage and distribute all economic activities in the value chain in order to take advantage of the value chain and maximize the value of new creations. The theory also holds that enterprises should focus on a certain part of their competitive value chain, cooperate with other enterprises in links that do not have advantages, complement each other's advantages, jointly improve value creation and value-added, and maximize overall returns. Therefore, value chain theory can explain the intentions of strategic alliances.

\subsection{The theory of synergy}

This theory holds that the value of the whole is greater than the sum of the values of the individual parts. Through the form of strategic alliance can make the enterprises produce complementary effects and synergies, and then make the alliance enterprises get great synergies. Most of the synergies between alliance enterprises are realized through the transfer of professional skills and knowledge sharing among enterprises. In addition, economies of scale through strategic alliances between enterprises are also an important source of synergies. When some kind of integration is strategically formed between the alliances, resulting in a positive feedback mechanism for synergies, the more stable the strategic alliance will be and the more sustainable the synergies will be ${ }^{[9]}$.

\subsection{The view of strategic choice}

According to the view of strategic choice, it is a strategic behavior for enterprises to seek strategic alliances to enhance their competitiveness. On the basis of strategic analysis, enterprises decide to adopt appropriate strategic behavior and competitive strategies, such as cost-leading strategy, differentiation strategy, target aggregation strategy, etc. 
These strategic behaviors and competitive strategies are the response of enterprises to their own competitive environment, but also the embodiment of their strategic objectives. Strategic alliance can enhance the competitiveness of enterprises from many aspects, especially the generation of economies of scale, division of labor refinement and market segmentation.

\section{THE PRACTICAL INTENTIONS OF STRATEGIC ALLIANCES}

Fundamentally speaking, there is only one goal of implementing strategic alliance, that is, to seek the lasting competitive advantage of enterprise development through the form of strategic alliance, so as to realize the strategic goal of enterprise. Based on the practice and development of today's enterprise strategic alliances, as well as some of the existing research results, we believe that the practical intentions of enterprise strategic alliances are mainly the following:

\subsection{Achieving the resource sharing}

The strategic gap hypothesis shows that the degree of development that enterprises can obtain by relying on their own strength is limited, and the single-player enterprises are very vulnerable to the limitation of enterprise resources. The strategic alliance makes the alliance enterprise realize a certain degree of resource sharing within the alliance, and keeps the enterprises outside the alliance closed, which provides the necessary conditions for the enterprise to obtain the competitive advantage. The sharing of resources between enterprises through strategic alliances can also optimize the allocation of resources, improve the social utilization rate of resources, and thus maximize the utility of resources-This is even more significant for those scarce critical resources ${ }^{[10]}$

\subsection{Pursuing common learning}

Learning new knowledge and skills is an important driving force for the growth and development of enterprises. In the face of advancing knowledge with the times and the rapidly changing competitive environment, enterprises must study hard and accept new knowledge, new skills, self-styled enterprises will eventually be eliminated by competition [11]. How to learn and learn what is an important issue for the enterprise, the strategic alliance answers this question: within the strategic alliance, the enterprises to maximize the learning of each other's know-how or some special ability, but also in a reasonable and safe scope to exchange their own advantages and capabilities; Learning among alliance enterprises is interactive, which helps to improve each other's common development.

\subsection{Entering a new market}

Economic globalization, world economic integration and the development of regional economic groupings make enterprises face not only a limited region, a domestic market, but also market opportunities and challenges in the international context. In the face of market opportunities, enterprises should adopt effective strategies to continuously expand the scope of the market, to grow enterprises; In the face of international challenges, enterprises should strengthen inter-enterprise cooperation based on their own advantages, to strengthen enterprises.

Strategic alliance is an effective way for enterprises to get bigger and stronger, and it is a common way for many multinational enterprises to enter the market by improving market coverage and breaking down regional trade barriers through strategic alliance. In addition, strategic alliances enable them to leverage their core strengths and gain the support of alliance partners in the short board area, thereby maximizing resource utilization, reducing costs, adapting more quickly to changes in the competitive environment and making strategic adjustments ${ }^{[12]}$.

\subsection{Achieving economies of scale and economies of scope}

Enterprises through endo-origin growth to achieve economies of scale is often not ideal: on the one hand, the scale of enterprise growth is slow, and limited by their own resources, capacity, etc., time-consuming and labor-consuming is not economical; On the other hand, the expansion of enterprise size must take into account the relevant provisions of anti-monopoly policy, even if the enterprise itself can continue to expand, but its size must be limited to the scope of antimonopoly policy. Compared with the endo-origin growth mode to achieve economies of scale, the organization of strategic alliances can achieve substantial expansion of enterprise size while maintaining the independence of the alliance enterprises: the size of enterprises has not increased, but the actual scope of activities of enterprises has been expanded by strategic alliances. This provides the possibility for inter-enterprise alliances to achieve economies of scale within the alliance. In addition, enterprises can make up for their own resources, capabilities and other shortcomings through strategic alliances, and successfully use the advantages of alliance partners to diversify their operations in order to obtain a considerable economies of scope ${ }^{[13]}$.

\subsection{Avoiding excessive competition}

Under the traditional concept of commercial competition, enterprises regard the competition activities between enterprises as a series of zero-sum games, in which the enterprises compete fiercely with existing and potential competitors and ends up defeating or being defeated. This kind of confrontation often leads to the failure of competing enterprises, and also causes the waste of social and enterprise resources. In fact, the competition between enterprises is interactive, enterprises in the process of mutual competition will also produce a certain degree of dependence. 
Competition and cooperation is a dialectical relationship, and competition does not exclude cooperation. From this point of view, strategic alliance is a better development model for enterprises: the establishment of strategic alliance straightens out the dialectical relationship of competition and cooperation between enterprises, is conducive to jointly maintaining an effective competitive order, and reduces the huge waste and loss caused by excessive competition.

\subsection{Achieving risk and cost-sharing}

Scientific and technological progress shortens the life cycle of products, accelerates the speed of product renewal, and makes the product's scientific and technological content higher and higher; In addition, higher technology content and production technology requirements bring more challenges to enterprises, high research and development costs, high research and development risks and uncertain revenue situation are far beyond the scope of individual enterprises bearing and controlling. Through the form of strategic alliances, enterprises can expand cooperation, effectively broaden information channels, cost segmentation and risk sharing, improve enterprise value and market adaptability - this is not available to a single enterprise ${ }^{[14]}$.

\section{CONCLUSION}

In a word, the competitive advantage of the enterprise strategic alliance in the aspects of system, technology, organization and idea is deep into the inside from the outside of the enterprise. On the basis of organizational learning, these competitive advantages are transformed into the core ideas and core competitiveness of enterprises. As a result, strategic alliances can actively realize a company's long-term competitive advantage and realize its value creation by enhancing its core competitiveness. The gain of strategic alliance competitive advantage will strengthen the core competence of the alliance cooperative enterprise, and thus enhance the competitive advantage of the alliance cooperative enterprise. The pursuit of competitive advantage has become a powerful driving force for active alliance, which leads to the rapid development of strategic alliance.

\section{REFERENCES}

[1] Sierra, M.Cauleydela. Managing Global Alliances: Key Steps for Successful Collaboration [M].England: Addison-Wesley, 1995.

[2] Porter M E. Competition in global industries [M].Harvard Business Press, 1986.

[3] Gulati R.Network location and learning: the influence of network resources and firm capabilities on alliance formation [J].Strategic Management Journal, 1999, 20 (5):397-420.

[4] REUER J J, RAGOZZINO R. Signals and international alliance formation: the roles of affiliations and international activities [J]. Jounal of International Business Studies, 2014, 45 (3):321-337.

[5] O.E.Williamson. The Economic Institutions Capitalism [M].New York : Free Press , 1985.

[6] Birger Wernerfelt. A Resource-based View of the Firm [J]. Strategic Management Journal , 1984,17 ( 5 ) : 171-180.

[7] Dorothy Leonard-Barton. Core Capabilities and Core Rigidities : A Paradox in Managing New Product Development[J].Strategic Management Journal , 1992,29 ( 13 ) : 111-125.

[8] C.Argyris, D.A.Schon. Organizational Learning : A Theory of Action Perspective [M].USA : Addison Wesley , 1978.

[9] Zhao Chang-ping, Wang Fang-hua, Ge Wei-hua. A study of the synergetic mechanism of the formation of strategic alliances [J].The Journal of Shanghai Jiao-tong University , 2004 , 38 ( 3 ) : 417-421.

[10] Steven W. Bradley, Howard Aldrich, Dean A. Shepherd, Johan Wiklund. Resources, environmental change, and survival-asymmetric paths of young independent and subsidiary organizations[J].Strategic Management Journal , 2010, 32 ( 19 ) : 486-509.

[11] Michael A. Hitt, M. Tina Dacin , Edward Levitas, Jean-Luc Arregle, Anca Borza. Partner selection in emerging and developed market contexts : Resource-based and organizational learning perspectives [J].The Academy of Management Journal , 2000 , 43 ( 3 ) : 449-467.

[12] Carolin Häussler. When Does Partnering Create Market Value[J].European Management Journal , $2006,24(1): 1-15$. 
[13] Luo Ding-ti, Liang Mei-hua. Select Cooperation - Value Analysis of Inter-Enterprise Partnerships [J]. Economic Forum , 2003, 6(13) : 29-31.

[14] Karen C. Denning, Heather Hulburt, Stephen P. Ferris. Risk and wealth effects of U.S. firm joint venture activity [J].Review of Financial Economics，2006，15 (12) : 271-285. 